\title{
A Novel Approach for Visual Representation of Animated Weather Station Data
}

\author{
Doğu Sirt ${ }^{1}$, Assoc. Prof. Dr. Mehmet Göktürk ${ }^{2}$ \\ ${ }^{1}$ Department of Computer Engineering, Gebze Technical University, Kocaeli, Turkey, dsirt@gtu.edu.tr \\ ${ }^{2}$ Department of Computer Engineering, Gebze Technical University, Kocaeli, Turkey, gokturk@ gtu.edu.tr
}

\begin{abstract}
Expert analysts interested in meteorology have a lot of complex situations while exploring and analyzing meteorological data visualization interfaces. According to previous researches, combining symbolic and realistic visualization methods in the direction of specific criterias are not found. In this paper, it is aimed to solve this problem with a better data visualization approach. As our starting point, visualization criterias are specified for a better visualization. After that the data belonging to meteorological variables (temperature, atmospheric pressure, humidity and wind speed and direction) gathered from both local and global weather stations are visually implemented for both symbolic $2 D$ and animated 2D. Giving expert analysts opportunity to experience our new generation visualization method, it is proven that symbolic $2 D$ visualization is not enough to meet today's visualization requirements. The approach that hybrid visualization provides a better visualization with predefined visualization criterias is verified.
\end{abstract}

Keywords: weather stations, data visualization, meteorological data visualization, symbolic visualization, realistic visualization.

\section{Introduction}

Today, scientific data visualization is widely used in many areas. In this context, weather data visualization under the title of scientific data visualization techniques aims to present meteorological variables in the most effective way for researchers to make them distinguish and evaluate elements according to their color, size or shape.

In this research area, it is aimed to make improvements on visualizing air temperature, atmospheric pressure, humidity and wind speed and direction etc. included in meteorological variables to prevent from bad visualization examples which cause troubles while evaluating the systems. Multi-field and physics-based visualization systems [1] [2] are emerged to create a realistic visualization based on the optical properties of the particles (illumination and scattering).

While visualizing wind speed and direction etc. with 2D vector based visualization methods, some inferences are made about curves are used to visualize variables in animated 2D and 3D environments [3].

Many different techniques are supported such as physics-based atmospheric rendering, illustrative rendering, particle and glyph rendering to provide flexible and efficient data analysis tools. These tools help expert analysts feel in an integrated atmospheric visual analysis and exploration environment[4].

In the context of cause-and-effect relationship, a robot arm is able to learn by the sense of touch (haptics) as well as the data provided by meteorological data visualization interfaces [5].

In the following period, a comprehensive study is contributed to the flow visualization technique by using static flow charts for visualization together with glyphs to provide better image representations. In this study, new techniques are also described for better visualization of meteorological variables such as pressure, wind speed and direction [6]. 
A new approach to visualize meteorological data is to use a GPU-supported Blender3D, a special program for creating variables. In addition, flowing dynamic particles are produced by using that special program [7].

The most original and comprehensive study that is realized in this area is about the performance comparison between flow visualization techniques and realization of them all as well as their day-to-day workflow [8].

As a result, it is not found in the literature that realistic and symbolic visualization methods are combined and used in the direction of a visual criterion system. In this framework, Section 2 summarizes the techniques of weather visualization, Section 3 describes the meteorological variables, Section 4 describes the method of visualizing and testing the data. In Section 5, the hypotheses are experimentally tested according to the method we propose. The results of the experiment are evaluated and discussed in Chapter 6.

\section{Weather Data Visualization}

Since our meteorological data includes symbolic and realistic visualization on the map, the definitions of visualization techniques which are used in experiments should be given in general terms.

\subsection{Flow Visualization}

The flow visualization is divided into four. These are animated streamlets, animated orthogonal particles, grid of arrows, and equally spaced streamlines [8].

\subsection{Volume Visualization}

Volume visualization is used to create two-dimensional graphical representations of numeric data sets. These are divided into two which are called direct volume rendering and surface fitting.

\subsection{Multidimensional Visualization}

Multidimensional data is a special case where some features are independent of each other. Such data is related to physical dimensions such as time and space [9].

\section{Meteorological Variables}

\subsection{Average Air Temperature}

The air temperature is calculated according to the values obtained at certain intervals from the stations. The units used in our work are ${ }^{\circ} \mathrm{C}$ and ${ }^{\circ} \mathrm{K}$. The temperature is calculated up to 2 meters above the ground.

\subsection{Atmospheric Pressure}

Atmospheric pressure is the pressure that air creates on the ground surface through gravity. The unit used in our work is $\mathrm{hPa}$. It is also called mbar to make it easier.

\subsection{The Amount of Humidity}

Water vapor in the air is called humidity. The basic unit is grams / cubic meter. It is expressed as a percentage in terms of widespread use in our study. There are three basic types of humidity:

- Humid: Shown as light blue in visualization.

- Perhumid (very humid): Shown as dark blue in visualization.

- Arid: Shown as yellow color in visualization.

\subsection{Wind speed and direction}

The wind speed is determined by the Beaufort wind scale ${ }^{1}$ in $\mathrm{km} / \mathrm{h}$ or knots. The map is able to revive the average wind speed and direction according to the altitude value up to 2 meters from the ground.

\section{Specifying Criteria and The Method}

${ }^{1}$ For further information please visit: https://en.wikipedia.org/wiki/Beaufort_scale 
The following hypotheses $\mathrm{H} 0$ and $\mathrm{H} 1$ are established to test the results generated in experimental sets:

- H0: 2D visualization methods are sufficient for satisfying criteria when all visual representations are evaluated.

- H1: The next generation visualization approach (Realistic + Symbolic), in which animation and particle system are used by defining special visualization criteria, provides more human-centered user experience than current approaches.

In our study, a survey is conducted by the help of 10 people working on Computer Science and Meteorology in the direction of Tufte's principles of excellence [10]. As a result, each meteorological variable is checked whether they satisfy the criteria or not:

- Human subjects can / cannot answer questions about weather conditions.

- Human subjects compare / cannot compare the values of the variables in a meaningful sense of perspective via the system interface.

- Human subjects explain / cannot explain the data set of the related variable with statistical and verbal definitions by the help of the system.

- Human subjects can / cannot make a clear distinction between hybrid visualization (Realistic + Symbolic) and Symbolic visualization (S).

- Human subjects like/do not like the visualization.

Both symbolic 2D and animated 2D visualizations are produced using Matlab on data gathered from NOAA (National Oceanic and Atmospheric Administration) and TARBIL (Agricultural Monitoring and Information System). Animated streamlets and animated orthogonal particles which are flow visualization techniques are used to visualize the wind speed and direction as well as heatmap and glyph etc.

Our work takes advantage of the inference on combining symbolic and realistic visualizations. GRID method is used for creating both hybrid (realistic and symbolic) and 2D symbolic visualization via Matlab environment.

Since our data is at a resolution of $1^{\circ} \times 1^{\circ}$, the world map is divided by degrees. By this way, it should be divided into separated grids according to the following equations.

$$
\begin{aligned}
\text { GLat } & =90:-1:-90 \\
\text { GLon } & =0: 359
\end{aligned}
$$

\section{Experiments}

Four experimental sets are prepared in which 10 human subjects participate. As shown in Fig. 1 on the 2D map, the initial state of the system is prepared in early stages. Creating basic drawings like continents, surface shapes, boundaries and determining the position of the desired region on the map and zooming on the determined position are added to the system. The two disjoint states on the map for evaluating our assumptions are:

- A visualization that includes a 2D flat map

- Animated 2D that combines symbolic (abstract) and realistic visualization elements.

\subsection{Experiment 1: Average Temperature}

The aim of this experiment, in which the average temperature variable is visualized in two different forms, is to make expert analysts discover the distinction between symbolic $(S)$ and hybrid $(G+S)$ visualization which are represented on the map. On the $2 \mathrm{D}$ visualization section of the experiment, the annual average temperature data from NOAA is plotted on a flat map using a contour map with heatmap technique. As for the Animated 2D visualization section of the experiment, heatmap is used with TARBIL data by animating temperature change. 

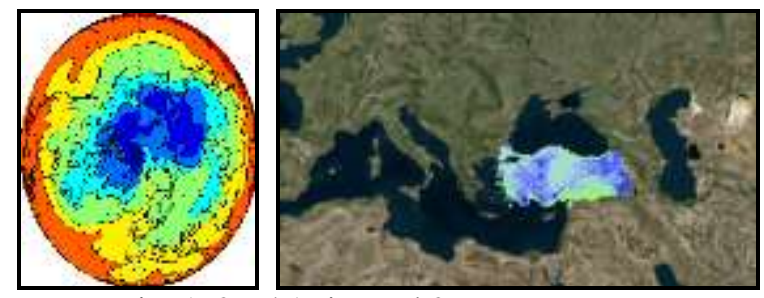

Fig. 1: 2D / Animated 2D Temperature

Statistics and total scores gathered from 10 expert analysts related to temperature variable are shown in Table I:

TABLE I: Average Temperature Scoring Table

\begin{tabular}{|c|c|c|c|c|c|c|}
\hline $\begin{array}{l}\text { 2D/ } \\
\text { Anim. 2D }\end{array}$ & $\begin{array}{l}\text { Very Bad } \\
\text { (1 pts) }\end{array}$ & $\begin{array}{l}\text { Bad } \\
(2 \mathrm{pts})\end{array}$ & $\begin{array}{l}\text { Neutr } \\
\text { (3 pts) }\end{array}$ & $\begin{array}{l}\text { Good } \\
\text { (4 pts) }\end{array}$ & $\begin{array}{l}\text { Very Good } \\
(5 \mathrm{pts})\end{array}$ & Person*pts \\
\hline Cri. I & $1 / 0$ per. & $1 / 0$ per. & 1/1 per. & $6 / 8$ per. & 1/1 per. & $35 / 40$ \\
\hline Cri. II & $1 / 1$ per. & $2 / 1$ per. & $1 / 2$ per. & 4/1 per. & $2 / 5$ per. & $34 / 38$ \\
\hline Cri. III & $1 / 1$ per. & $1 / 1$ per. & $2 / 1$ per. & $2 / 1$ per. & 4/6 per. & $37 / 40$ \\
\hline Cri. IV & $1 / 1$ per. & $2 / 0$ per. & 4/1 per. & $2 / 1$ per. & $1 / 7$ per. & $30 / 43$ \\
\hline Cri. V & $1 / 0$ per. & $1 / 0$ per. & 3/1 per. & $4 / 3$ per. & $2 / 6$ per. & $38 / 45$ \\
\hline
\end{tabular}

\subsection{Experiment 2: Atmospheric Pressure}

The atmospheric pressure variable is also visualized in two different ways, as in the case of average temperature change. Fig. 2 which represents the correlation between average temperature and wind speed is implemented by using the global pressure data. The pressure data is visualized by NOAA data via Matlab environment. So the maximum data representation capacity that symbolic approach has is shown by the help of the following Fig. 2.

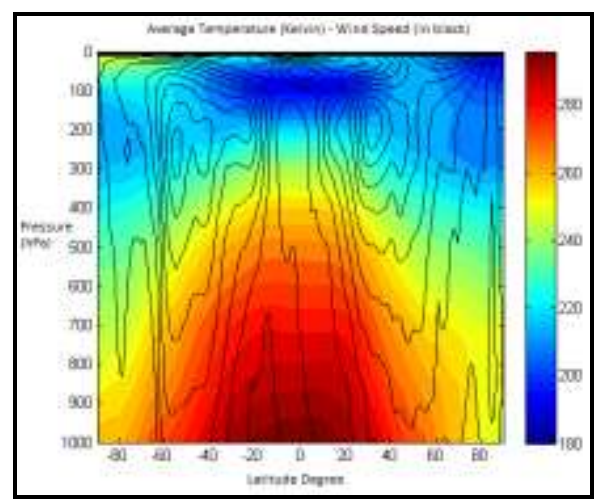

Fig. 2: 2D / Animated 2D Temperature

In the realistic version of the same experiment, animated 2D representation of TARBIL data is added and animated via streaming particle elements. Both temporal and spatial representations are presented in animated 2D format with Fig. 3. This provides an analytical approach to the atmospheric pressure visualization problem by completing two different visualizations of the same period of time.

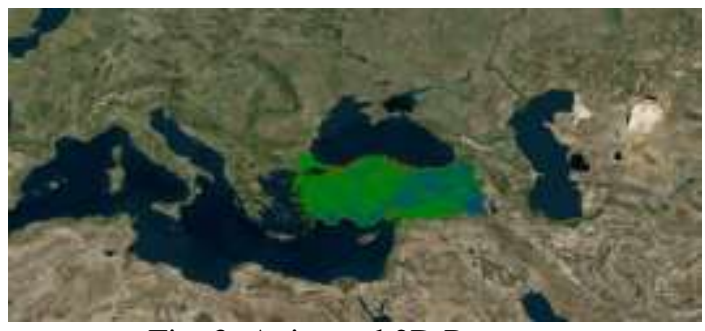

Fig. 3: Animated 2D Pressure 
Statistics and total scores gathered from 10 expert analysts related to atmospheric pressure variable are shown in Table II:

TABLE II: Atmospheric Pressure Scoring Table

\begin{tabular}{|c|c|c|c|c|c|c|}
\hline $\begin{array}{l}\text { 2D/ } \\
\text { Anim. 2D }\end{array}$ & $\begin{array}{l}\text { Very Bad } \\
(1 \mathrm{pts})\end{array}$ & $\begin{array}{l}\text { Bad } \\
(2 \mathrm{pts})\end{array}$ & $\begin{array}{l}\text { Neutr } \\
(3 \mathrm{pts})\end{array}$ & $\begin{array}{l}\text { Good } \\
\text { (4 pts) }\end{array}$ & $\begin{array}{l}\text { Very Good } \\
(5 \mathrm{pts})\end{array}$ & Person*pts \\
\hline $\begin{array}{l}\text { Cri. I } \\
\text { Cri. II }\end{array}$ & $\begin{array}{l}0 / 0 \text { per. } \\
1 / 0 \text { per. }\end{array}$ & $\begin{array}{l}1 / 0 \text { per. } \\
0 / 1 \text { per. }\end{array}$ & $\begin{array}{l}3 / 1 \text { per. } \\
3 / 2 \text { per. }\end{array}$ & $\begin{array}{l}4 / 8 \text { per. } \\
3 / 0 \text { per. }\end{array}$ & $\begin{array}{l}\text { 2/1 per. } \\
3 / 7 \text { per. }\end{array}$ & $\begin{array}{l}37 / 40 \\
37 / 38\end{array}$ \\
\hline Cri. III & $0 / 0$ per. & $2 / 1$ per. & $3 / 0$ per. & $2 / 1$ per. & $3 / 8$ per. & $36 / 46$ \\
\hline Cri. IV & $1 / 1$ per. & $1 / 2$ per. & $2 / 2$ per. & $3 / 1$ per. & $3 / 4$ per. & $36 / 35$ \\
\hline Cri. V & $1 / 0$ per. & $1 / 0$ per. & $3 / 1$ per. & $1 / 2$ per. & $4 / 7$ per. & $36 / 46$ \\
\hline
\end{tabular}

\subsection{Experiment 3: The Amount of Humidity}

In this experiment, in which humidity variable is visualized in two different forms, the visualization criteria are handled to be experienced in terms of the amount of humidity.

In the section containing 2D visualization, the data of Marmara region taken from the Istanbul/Eskice station (TARBIL Code: 34.01 ) is visualized by heatmap technique on a 2D flat map.

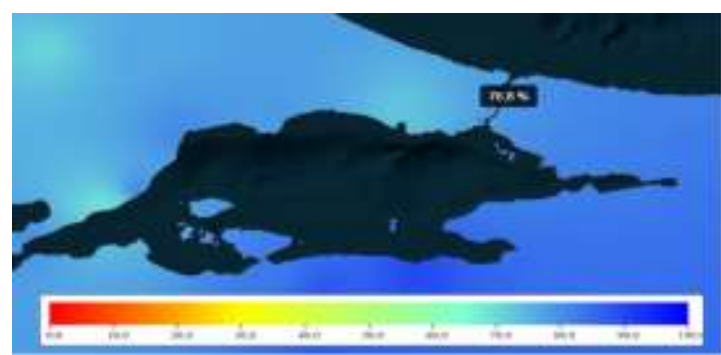

Fig. 4: 2D Humidity

In the realistic version of the same experiment, the TARBIL data is represented in animated 2D structure and the system motion map is added as in Fig. 5. Observations are carried out via Matlab environment by recording the change of the data in certain periods of time. The expert analyst uses this efficient tool for selecting related interval focusing on day and month on the timeline.

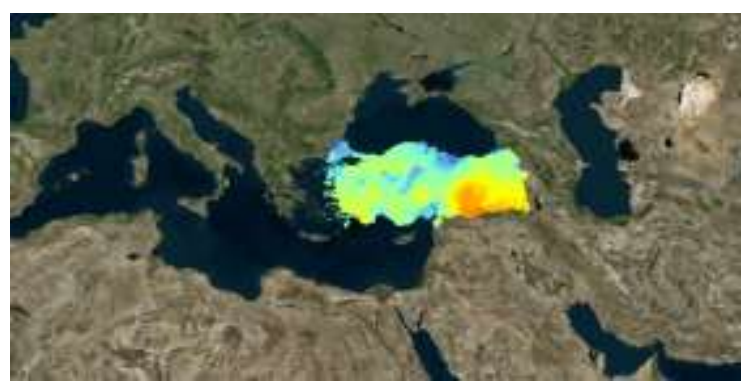

Fig. 5: Animated 2D Humidity

Statistics and total scores gathered from 10 expert analysts related to humidity variable are shown in Table III:

TABLE III: Humidity Scoring Table

\begin{tabular}{lllllll}
\hline \hline 2D/ & Very Bad & Bad & Neutr & Good & Very Good & Person*pts \\
Anim. 2D & $(1 \mathrm{pts})$ & $(2 \mathrm{pts})$ & $(3 \mathrm{pts})$ & $(4 \mathrm{pts})$ & $(5 \mathrm{pts})$ & \\
\hline Cri. I & $1 / 0$ per. & $2 / 0$ per. & $0 / 1$ per. & $7 / 8$ per. & $0 / 1$ per. & $33 / 40$ \\
Cri. II & $0 / 1$ per. & $2 / 1$ per. & $2 / 2$ per. & $2 / 1$ per. & $4 / 5$ per. & $38 / 38$ \\
Cri. III & $0 / 0$ per. & $0 / 1$ per. & $0 / 2$ per. & $4 / 1$ per. & $6 / 6$ per. & $46 / 42$ \\
Cri. IV & $0 / 1$ per. & $0 / 1$ per. & $2 / 1$ per. & $5 / 1$ per. & $3 / 6$ per. & $41 / 40$ \\
Cri. V & $1 / 0$ per. & $1 / 1$ per. & $1 / 2$ per. & $4 / 3$ per. & $3 / 4$ per. & $37 / 38$ \\
\hline \hline
\end{tabular}




\subsection{Experiment 4: Wind Speed and Direction}

In the experiment containing symbolic part of $2 \mathrm{D}$ visualization, the data derived from NOAA is visualized in the Matlab environment as before. The global wind direction shown in Fig. 6 is the first step to visualize the NOAA-derived data on the map. Then the symbolic 2D visualization of the variable is obtained with zooming in/out to the related continent, region or country. This is also a powerful tool for exploration and evaluation for expert analysts.

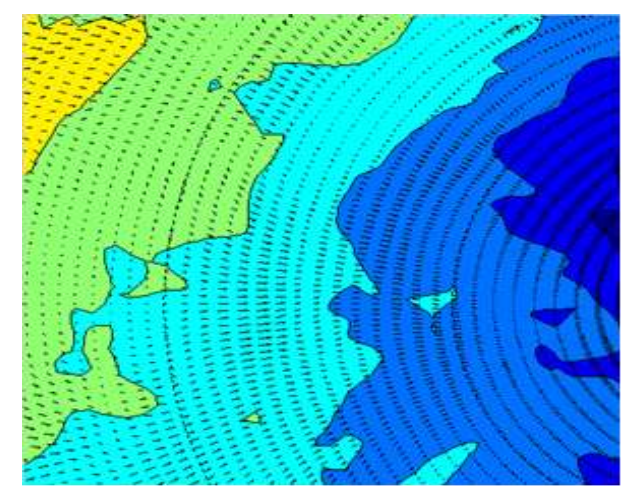

Fig. 6: 2D Wind Speed and Direction

In Fig. 7, which is the realistic 2D version of the same experiment, the NOAA data is also in animated 2D format prepared in the Matlab environment. The difference is the addition of streaming animated particles to the visualization. Moreover, information of the wind speed is shown in $\mathrm{m} / \mathrm{s}$ unit of the point focused on the graphical interface. This data is able to be presented to the expert analyst in real time.

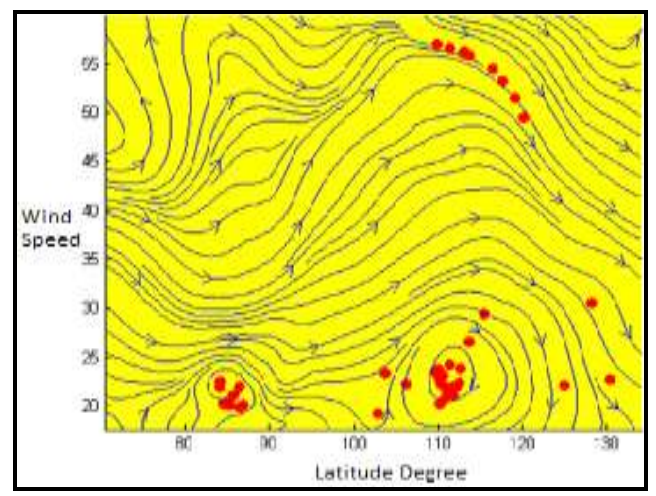

Fig. 7: Animated 2D Wind Speed and Direction

Statistics and total scores gathered from 10 expert analysts related to temperature variable are shown in Table IV:

TABLE IV: Wind Speed and Direction Scoring Table

\begin{tabular}{|c|c|c|c|c|c|c|}
\hline $\begin{array}{l}\text { 2D/ } \\
\text { Anim. 2D }\end{array}$ & $\begin{array}{l}\text { Very Bad } \\
(1 \mathrm{pts})\end{array}$ & $\begin{array}{l}\mathrm{Bad} \\
(2 \mathrm{pts})\end{array}$ & $\begin{array}{l}\text { Neutr } \\
(3 \mathrm{pts})\end{array}$ & $\begin{array}{l}\text { Good } \\
\text { (4 pts) }\end{array}$ & $\begin{array}{l}\text { Very Good } \\
(5 \mathrm{pts})\end{array}$ & Person*pts \\
\hline $\begin{array}{l}\text { Cri. I } \\
\text { Cri. II }\end{array}$ & $\begin{array}{l}0 / 0 \text { per. } \\
1 / 0 \text { per. }\end{array}$ & $\begin{array}{l}3 / 0 \text { per. } \\
2 / 0 \text { per. }\end{array}$ & $\begin{array}{l}1 / 2 \text { per. } \\
1 / 1 \text { per. }\end{array}$ & $\begin{array}{l}5 / 0 \text { per. } \\
4 / 0 \text { per. }\end{array}$ & $\begin{array}{l}1 / 8 \text { per. } \\
2 / 9 \text { per. }\end{array}$ & $\begin{array}{l}34 / 46 \\
34 / 48\end{array}$ \\
\hline Cri. III & $1 / 1$ per. & $1 / 1$ per. & $2 / 0$ per. & $2 / 4$ per. & 4/4 per. & $37 / 39$ \\
\hline Cri. IV & $0 / 0$ per. & $2 / 0$ per. & $1 / 1$ per. & $3 / 3$ per. & $4 / 6$ per. & $39 / 45$ \\
\hline Cri. V & $1 / 0$ per. & $1 / 1$ per. & $3 / 2$ per. & $3 / 2$ per. & $2 / 5$ per. & $34 / 41$ \\
\hline
\end{tabular}

\section{Discussion and Conclusion}

Hybrid visualization $(\mathrm{G}+\mathrm{S})$ in Experiment 1, 2, 3 and 4 produces a big difference compared with symbolic visualization (S) by all means. Nevertheless, it becomes a problem for some expert analysts to give meaning to 
repeated animation at certain intervals as in wind speed and direction experiment. The same situation goes also for the 2D symbolic visualizations obtained with NOAA and TARBIL data. There is no one that is able to distinguish symbolic and realistic visualization except for a small minority as it is possible to deduce from scoring tables.

When it is taken into consideration as a whole, our H0 hypothesis that the symbolic 2D visualization is sufficient when all of the existing techniques are used is rejected and refuted for all meteorological variables. Our H1 hypothesis is confirmed according to the experiments performed. Hybrid visualization techniques are more popular and liked by expert analysts than symbolic visualizers. This shows us hybrid visualization is better than just only symbolic visualization when a special sort of visual criterion system is applied to meteorological variables.

\section{Acknowledgment}

We would like to thank Gebze Technical University Computer Engineering Department, TARBIL Project Staff and Istanbul Technical University MoSim (Modeling and Simulation Research Group) for their kind cooperation.

\section{References}

[1] Riley, K., Ebert, D., Hansen, C., Levit, J. (2003), Visually Accurate Multi-Field Weather Visualization, Proceedings of IEEE Visualization 2003, 279-286.

https://doi.org/10.1109/visual.2003.1250383

[2] Riley, K., Ebert, D., Hansen, C., Levit, J., (2004), A System for Realistic Weather Rendering, Proceedings of the 84th American Meteorological Society Annual Meeting, January. Nielsen J:Noncommand user interfaces. Commun ACM36, 4(Apr.1993),83-99

[3] Laidlaw, D. H., et al. (2005), Comparing 2D vector field visualization methods: A user study. IEEE Transactions on Visualization and Computer Graphics, 11.1: 59-70. https://doi.org/10.1109/TVCG.2005.4

[4] Song, Y., Yi, J., Svakhine, N., et al. (2006), "An Atmospheric Visual Analysis and Exploration System," IEEE Transactions on Visualization and Computer Graphics, Vol. 12, No. 5.

https://doi.org/10.1109/TVCG.2006.117

[5] Yannier N., Basdogan C., Tasiran S., Sen O. L., 2008, Using Haptics to Convey Cause-and-Effect Relations in Climate Visualization, IEEE Transactions on Haptics, vol. 1, no. 2, pp. 130-141. https://doi.org/10.1109/TOH.2008.16

[6] Pilar, D. H. F., Ware, C. (2013), Representing flow patterns by using streamlines with glyphs. IEEE transactions on visualization and computer graphics, 19.8: 1331-1341.

https://doi.org/10.1109/TVCG.2013.10

[7] Hakstok I., Mihajlović Z., (2014), "Visualization of meteorological data," 2014 37th International Convention on Information and Communication Technology, Electronics and Microelectronics (MIPRO), Opatija, pp. 406-410. https://doi.org/10.1109/MIPRO.2014.6859600

[8] Ware C., et. al. (2016), Animated versus static views of steady flow patterns. In Proceedings of the ACM Symposium on Applied Perception (SAP '16). ACM, New York, NY, USA, 77-84 Vandam A.: Post-wimp user interfaces. Commun. ACM 40, 2 (Feb. 1997), 63-67.

https://doi.org/10.1145/2931002.2931012

[9] Fuchs, R., Hauser, H. (2009), Visualization of Multi-Variate Scientific Data. In: Computer Graphics Forum. Blackwell Publishing Ltd, p. 1670-1690. https://doi.org/10.1111/j.1467-8659.2009.01429.x

[10] Tufte E. R. (2001), The Visual Display of Quantitative Information, 2nd Edition. Graphics Press, Cheshire, Connecticut,.

[11] www.tarbil.org / Agricultural Monitoring and Information System

[12] www.noaa.gov / National Oceanic and Atmospheric Administration 